\title{
RETRACTED ARTICLE: Attractive interactions prevail in dilute solutions of human recombinant $\alpha$-crystallins
}

\author{
Yannis Georgalis · Jirka Peschek • \\ Marie-Sousai Appavou
}

Received: 10 August 2012/Revised: 26 November 2012/ Accepted: 11 December 2012/Published online: 10 January 2013

(C) European Biophysical Societies' Association 2013

The Authors in agreement with the Editor-in-Chief of the "European Biophysics Journal", the European Biophysical Societies' Association, and the publisher hereby retract the article entitled "Attractive interactions prevail in dilute solutions of human recombinant $\alpha$-crystallins" by Georgalis Y, Peschek J, Appavou MS; published online in the "European Biophysics Journal" on January 10, 2013. This article is retracted due to unsolved legal reasons.

Y. Georgalis

Department of Chemistry, Technische Universität München,

Lichtenbergstrasse 4, 85747 Garching, Germany

J. Peschek

Center for Integrated Protein Science, Technische Universität

München, Lichtenbergstrasse 4, 85747 Garching, Germany

M.-S. Appavou ( $\square)$

Jülich Center for Neutron Science at FRMII, Lichtenbergstrasse

1, 85747 Garching, Germany

e-mail: m.s.appavou@fz-juelich.de

URL: http://iffwww.iff.kfa-juelich.de/var/Mitarbeiter/

e_jcns_frm_staff.html 